\title{
Finding connections in the unexpected detection of Plasmodium vivax and Plasmodium falciparum DNA in asymptomatic blood donors: a fact in the Atlantic Forest
}

\author{
Maria Anice Mureb Sallum ${ }^{1 *}$, Cláudio Tadeu Daniel-Ribeiro ${ }^{2 *}$, Gabriel Zorello Laporta', \\ Maria de Fátima Ferreira-da-Cruz ${ }^{2}$, Luciana Morganti Ferreira Maselli, ${ }^{3,4}$, Débora Levy ${ }^{4}$ and Sérgio Paulo Bydlowski ${ }^{4^{*}}$
}

\begin{abstract}
A recent paper in Malaria Journal reported the observation of unexpected prevalence rates of healthy individuals carrying Plasmodium falciparum (5.14\%) or Plasmodium vivax (2.26\%) DNA among blood donors from the main transfusion centre in the metropolitan São Paulo, a non-endemic area for malaria. The article has been challenged by a group of authors who argued that the percentages reported were higher than those found in blood banks of the endemic Amazon Region and also that that paper had not considered the literature on the classical dynamics of malaria transmission in the Atlantic Forest, which involves Anopheles (Kerteszia) cruzii and bromeliad malaria, due to $P$. vivax and Plasmodium malariae parasites, but not $P$. falciparum. The present commentary paper responds to this challenge and brings evidence and literature data supporting that the observed prevalence ratios may indicate a proportion of individuals that are exposed to Plasmodium transmission in permissive environments; that blood carrying parasite DNA may not be necessarily infective if used in transfusion; and that in the literature, there are examples supporting the circulation of $P$. falciparum in the area.
\end{abstract}

Keywords: Malaria, Plasmodium falciparum, Plasmodium vivax, Subclinical infection, Blood donors, Atlantic Forest

\section{Background}

The dynamics of malaria in the Brazilian Atlantic Forest seems to represent ideal, low transmission settings that involve patterns of evolution of Plasmodium parasites, its hosts and its vectors. Evidence of subclinical plasmodial infection in inhabitants and visitors of forest areas indicate that the dynamics of malaria may have reached a sustainable transmission level, without causing morbidity and affecting the survival of hosts, reservoirs and vectors. Following the intensive and successful malaria-eliminating programme from the 1950s onwards, Plasmodium falciparum and Plasmodium vivax

\footnotetext{
*Correspondence: masallum@usp.br; malaria@fiocruz.br; spbydlow@usp.br 'Departamento de Epidemiologia, Faculdade de Saúde Pública, Universidade de São Paulo, São Paulo SP 01246-904, Brazil

2Laboratório de Pesquisa em Malária, Instituto Oswaldo Cruz, Fiocruz, Rio de Janeiro RJ 21045-900, Brazil

${ }^{4}$ Laboratório de Genética e Hematologia Molecular (LIM31), Faculdade de Medicina da Universidade de São Paulo, São Paulo SP 05403-000, Brazil Full list of author information is available at the end of the article
}

reservoirs and mosquito vectors may have remained clustered in small geographical areas that maintain the circulation of the Laverania protozoan without the costs of malaria burden. This ideal evolution scenery needs further investigations in order to find connections in the unexpected high prevalence ratio of asymptomatic infection in humans exposed to forest environments. The study by Maselli et al. [1] points to the maintenance of P. falciparum in the Atlantic Forest in silent cycles that may involve non-human primates, humans and mosquito vectors with distinct biology and ecological features, beyond the classical Kerteszial bromeliad malaria transmission dynamics.

Fully understanding malaria transmission represents a challenge for the disease control and the maintenance of the effectiveness of interventions. In countries where malaria was successfully eliminated, the epidemiology of the disease becomes more complex [2]. It is, therefore, possible to assume that after an exhaustive, successful 
control, the residual malaria in the Atlantic Forest may encompass distinct dynamics of transmission. In this biome, the epidemiology of malaria seems to be determined by biologically distinct vectors, wild non-human primates and humans, in a conducive, heterogeneous environment.

Among more than 400 anophelines, approximately 70 species [3] can transmit the six Apicomplexan protozoan of the genus Plasmodium that can infect and cause malaria in humans, P. falciparum, P. vivax, Plasmodium knowlesi, Plasmodium malariae, Plasmodium ovale curtisi and Plasmodium ovale wallikeri [4]. Sinka [3] clearly shows that in Brazil, in addition to Anopheles cruzii other species of the subgenera Anopheles, Kerteszia and Nyssorhynchus are potential vectors of Plasmodium protozoans. Considering that members of the three subgenera are biologically and ecologically distinct, the dynamics of malaria in Brazilian ecosystem seems to encompass complex dynamics.

According to Begon [5], a parasite is an "organism that obtains its nutrients from one or a very few hosts", whereas a pathogen is "any parasite that gives rises to a disease". Additionally, Begon argues that both a parasite and a host population have their own interacting dynamics. Consequently, the knowledge of epidemiology of malaria may address the determinants associated to humans, mosquitoes, Plasmodium protozoan (that can behave either as parasite or pathogen) and other potential host/reservoir populations.

The origin and evolutionary history of $P$. falciparum has been subject of recent studies and a seminal work on Plasmodium changed the paradox of the origin of the human P. falciparum. By testing faeces samples from wildliving apes throughout central Africa, Liu et al. [6] showed that Plasmodium infections were highly prevalent and widely distributed in the region. Moreover, western gorillas (Gorilla gorilla) were infected with a Plasmodium nearly identical to $P$. falciparum. Results of phylogenetic analyses using mitochondrial genome sequences showed that human $P$. falciparum clustered within gorilla P. falciparum lineage, indicating that the parasite is of gorilla origin. Rayner et al. [7] proposed the name G1 for the phylogenetic lineage that included Plasmodium parasites from the subgenus Laverania, i.e., human P. falciparum and $P$. praefalciparum for the parasites from gorillas as precursor of human P. falciparum. Based on evidence that the gorilla $P$. falciparum has been transferred to humans, it is possible that additional cross-species transfer has occurred in other regions where nonhuman primates live in close association with other potential reservoirs. Garamszegi [8] suggested that parasites may preferentially infect hosts that provide adequate conditions for their reproduction. Furthermore, Sharp et al. [9] predicted that the emergence of P. falciparum was likely caused by changes in human demography and behaviour that opened new niches that cause the emergence of the parasite in humans. In agreement, Silva et al. [10] suggested that ape infections with $P$. falciparum-like parasites are a consequence of deforestation and land use. These intensive ecological changes brought humans in close contact with wildliving apes, facilitating the transmission of parasites among infected apes and susceptible humans, and the other way around.

In Brazil, the Atlantic Forest biome has undergone massive and intensive ecological changes since the beginning of European colonization in the Sixteen Century [11]. Currently, it is estimated that only $11.4-16.0 \%$ of the original forest cover remains, most as fragments [12]. As a consequence of the fragmentation, humans and wild non-human primates may be in contact. This situation seems to occur in forest-fragmented regions of the Atlantic Forest, for instance in Juquitiba municipality, in areas of the northeastern coast of the São Paulo state, and in the southern of the São Paulo municipality. In the Parelheiros subdistrict of the São Paulo municipality, there are small fragments of Atlantic Forest, where autochthonous $P$. vivax malaria were notified (see [13]) and a few mosquito species other than An. cruzii were tested positive for the parasite [14].

In cross sectional study by Maselli et al. [1], the blood donors that had plasmodial infection either lived in areas of the east region of São Paulo state or had visited localities situated on the coast where most of the forest fragment remains. In striking contrast with the classical bromeliad-malaria model [15], most of the subclinical infections were associated with $P$. falciparum. Likely, the positivity observed was a consequence of a single template TaqMan-based real-time PCR with specific probes for each Plasmodium species adopted as the standard protocol for testing blood samples. The single template real time PCR that tested positive for $P$. falciparum (prevalence of $P f=5.14$ ) of the blood donors is indicating that a $P$. falciparum or $P$. falciparum-like parasite is infecting humans without causing disease. Three evidences corroborate this hypothesis. The first one is a single case of $P$. falciparum malaria among 14 autochthonous malarious patients from areas of the Atlantic Forest that were diagnosed and treated at the Instituto Nacional de Infectologia Evandro Chagas in Fiocruz (from 2008 to 2013). All 14 patients had acute vivax malaria, and a single patient was found infected by both $P$. falciparum and P. vivax. This makes possible that the $P$. falciparum infection was detected coincidentally only as a consequence of the concomitant (symptom-inducing) P. vivax infection (Pina-Costa, Doctoral Thesis, Instituto Nacional de Infectologia, Fiocruz, August 2014). The second evidence is provided by a recent publication by Abkallo 
et al. [16], showing that Plasmodium DNA from a preerythrocytic stage can be detected both in blood and faeces from infected non-human primates in the absence of blood stage parasites. This event, indicating that not all infected blood from non-human primates are infectious, could also occur in humans and is particularly important because it could partially explain the contrast between the inobservance of $P$. falciparum transfusional malaria cases in an area where an unexpected frequency of PCR positive for this parasite was registered. Finally, the third evidence comes from the confirmation of twenty-four randomly drawn P. falciparum positive blood samples retested by nested-PCR at the Laboratório de Pesquisa em Malária, Instituto Oswaldo Cruz, Fiocruz, according to the protocol of Zalis et al. [17]. Consequently, in view of the results reported by Maselli et al. [1] and the recent data quoted above, it seems evident that the dynamics of malaria in the Atlantic Forest is poorly known and needs further investigations, including studies relative to mosquito vectors and other determinants of the transmission, i.e., infectiveness and pathogenicity of the Plasmodium lineages that are circulating in the region, duration of infection in untreated individuals, duration of sporogony and gametocytogony, as discussed by Wernsdorfer [18].

Maselli et al. [1] have taken into account both the classical (bromeliad-malaria) and alternative patterns of the dynamics of malaria in the Atlantic Forest. However, the finding of $P$. falciparum DNA in blood donors in São Paulo suggests that the traditional dynamics of bromeliad-malaria is not the only one that can explain the presence of Plasmodium in areas of the Atlantic Forest in the state of São Paulo. Two major determinants of the bromeliad-malaria are the Anopheles (Kerteszia) mosquitoes and other Plasmodium species that do not belong to the subgenus Laverania. Cerruti et al. [19] addressed aspects of malaria in mountainous areas of the Espírito Santo state and hypothesized that, in the region, species of the subgenus Nyssorhynchus of Anopheles may be also involved in cycle of Plasmodium transmission. Thus, the results reported by Cerutti et al. [20] indicate, in agreement with the data of Maselli et al. [1], that a distinct dynamics of Plasmodium transmission could also occur in addition to the classical bromeliad-malaria.

Still considering the arguments against the presence of P. falciparum in Atlantic Forest by Mendrone et al. [20], it is worth noting that antibodies specific to the circumsporozoite protein (CSP) of P. falciparum have been detected in simians from the Atlantic Forest in São Paulo state [21]. Moreover, Yamasaki et al. [22] surveyed monkeys from Atlantic Forest for Plasmodium infection, and concluded that the high proportion of positive sera against the CSP of $P$. falciparum was uncommon. It is interesting to point that Malafronte, a coauthor of the study byYamasaki et al., also coauthored the paper by Mendrone et al. [20]. Additional support for the presence of $P$. falciparum in areas of Atlantic Forest, have been provided by Duarte et al. [23], who showed by PCR amplification that $1.4 \%$ of monkeys that tested positive for plasmodial infection had P. falciparum DNA. More important, the authors also surveyed monkeys both from urban areas and forest fragments in the vicinities of the municipality of São Paulo. Consequently, the arguments by Mendrone et al. [20] against the presence of $P$. falciparum are not supported by the data published in the literature.

The observation of asymptomatic individuals carrying $P$. falciparum DNA in higher prevalence among blood donors of a São Paulo Transfusion Center than in blood banks from the Amazon region is as intriguing as difficult to explain. However, if $P$. falciparum is circulating in areas of the Atlantic Forest in non-human primates and humans, it is plausible to assume that there are also mosquitoes infected with $P$. falciparum. The reasons for the lack of report of mosquitoes naturally-infected with $P$. falciparum are unknown; however, it is possible that the absence is, at least partially, explained by the methods employed to test mosquitoes, usually in pools $[14,24]$.

Cerutti et al. [19] employed immunofluorescence antibody test (IFAT) to observe a high percentage of human inhabitants of the Atlantic Forest of Espírito Santo state positive for IgM (13.5\%) and IgG (13\%) antibodies to $P$. falciparum. In addition, the authors reported nine individuals positive for $P$. falciparum by multiplex-PCR, and concluded that "the puzzling finding of P. falciparum DNA by multiplex PCR in asymptomatic individuals" and, more important, quoted that "the possibility of false positive results is remote as no other samples infected by $P$. falciparum were processed by PCR in the laboratory at the time of the study, thus ruling out the possibility of any cross-contamination". Consequently, the argument by Mendrone et al. [20] that "DNA supposed to be from $P$. falciparum... did not usually resist to a second amplification by another method" is not supported by data presented by team of his coauthor.

Mendrone et al. [20] also challenged the results of Maselli et al. [1] by arguing that in a PhD thesis associated to the article, an ELISA assay was utilized for testing the blood donors and the results were not included in the paper. This information is not incorrect. The thesis is authored by Aline Monteiro, one of the coauthors of the paper by Maselli et al. [1]. Although described as more sensitive than IFAT, the gold standard to estimate malarial antibody titers, the analytical sensitivity of ELISA-Malaria antibodies test kit from DiaMed (product 46460) was 40\% with specificity of $98.3 \%$, when tested in 923 malaria risk donors. According to Doderer et al. [25], the large number of non-concordant results between ELISA and IFAT 
impaired the performance of this DiaMed kit. Oh et al. [26] also reported that this test was insufficiently sensitive for blood screening for P. vivax. In addition to the described low performance of the DiaMed malarial kit, it has not been systematically tested regarding its sensitivity in low parasitaemia infection, it has not been approved by the Brazilian Agência de Vigilância Sanitária (Anvisa) and the kit production was interrupted. All these points were discussed in the thesis. Therefore, taking into account the negative features of the DiaMed kit, including its low sensitivity and inadequacy to detect subclinical infection, the results of the ELISA assays were considered inconsistent for publication.

Regarding mistakes in the references, the authors were aware of them and submitted an Erratum comment to the journal immediately after publication, which remains attached to the paper. This Erratum consists of a full list of corrections, including the correct number of autochthonous cases in São Paulo, and the fact that the Perandin et al. [27] citation replaces Gama et al. [28].

\section{Conclusions}

The article by Maselli et al. [1] poses quite different challenges and has the merit of showing the presence of $P$. falciparum among asymptomatic blood donors and to emphasize that the current knowledge of malaria transmission in the Atlantic Forest domain is far too limited. The natural history of $P$. falciparum malaria in the Atlantic Forest is either poorly known or even unknown, including its vectors, hosts and reservoirs, both in spatial and temporal scales. There is an urgent need to improve the knowledge of the biotic and abiotic determinants as well as the natural history of the disease, before speculating and proposing any strict epidemiological profile for the dynamics of the $P$. falciparum in the biome. Most of the arguments by Mendrone et al. [20] regarding the discoveries of Maselli et al. [1] are based on the rationale that the results published are not supported by previous publications. On the contrary, it has been shown here that part of the previous published literature showed the same evidence. In agreeing with Thierry Maulnier, who says that "it would be unwise to believe that what never happened is impossible", the reasoning by Mendrone et al. may be considered weak. Indeed, defending a stable and unchangeable pattern of bromeliad malaria, which was proposed in the 1940s and 1960s, to explain the malaria transmission in the Atlantic Forest now, is to deny any evolutionary processes that can drive the dynamics of the transmission of Plasmodium in a changing world.

\section{Competing interests}

The authors declared that they have no competing interests.

\section{Authors' contributions}

MAMS, CTDR and SPB conceived the ideas and wrote the manuscript with the help from GZL, MFFC, LMFM and DL. All authors read and approved the final version of the manuscript.

\section{Acknowledgments}

To Fundação de Amparo à Pesquisa no Estado de São Paulo (FAPESP, grant no. 2011/20397-7 to MAMS).

\section{Author details}

${ }^{1}$ Departamento de Epidemiologia, Faculdade de Saúde Pública, Universidade de São Paulo, São Paulo SP 01246-904, Brazil. ²Laboratório de Pesquisa em Malária, Instituto Oswaldo Cruz, Fiocruz, Rio de Janeiro RJ 21045-900, Brazil. ${ }^{3}$ Fundação Pró-Sangue Hemocentro de São Paulo, Faculdade de Medicina da Universidade de São Paulo, São Paulo SP 05403-000, Brazil. ${ }^{4}$ Laboratório de Genética e Hematologia Molecular (LIM31), Faculdade de Medicina da Universidade de São Paulo, São Paulo SP 05403-000, Brazil.

Received: 15 August 2014 Accepted: 19 August 2014 Published: 28 August 2014

\section{References}

1. Maselli LMF, Levy D, Laporta GZ, Monteiro AM, Fukuya LA, Ferreira da Cruz MF, Daniel-Ribeiro CT, Dorlhiac-Llacer PE, Sallum MAM, Bydlowski SP: Detection of Plasmodium falciparum and Plasmodium vivax subclinical infection in non-endemic region: implications for blood transfusion and malaria epidemiology. Malar J 2014, 13:224.

2. Cotter C, Sturrock HJ, Hsiang MS, Liu J, Phillips AA, Hwang J, Gueye CS, Fullman N, Gosling RD, Feachem RG: The changing epidemiology of malaria elimination: new strategies for new challenges. Lancet 2013 382:900-911. Erratum in Lancet 2013, 382:858.

3. Sinka ME: Global Distribution of the Dominant Vector Species of Malaria, Anopheles mosquitoes. In New insights into malaria vectors. Edited by Manguin S. Rijeka: InTech; 2013. doi:10.5772/54163. Available from: http://www.intechopen.com/books/anopheles-mosquitoes-new-insightsinto-malaria-vectors/global-distribution-of-the-dominant-vector-species-ofmalaria. ISBN 978-953-51-1188-7.

4. Sutherland CJ, Tanomsing N, Nolder D, Oguike M, Jennison C, Pukrittayakamee S, Dolecek C, Hien TT, do Rosário VE, Arez AP, Pinto J, Michon P, Escalante AA, Nosten F, Burke M, Lee R, Blaze M, Otto TD, Barnwel JW, Pain A, Williams J, White NJ, Day NPJ, Snounou G, Lockhart PJ, Chiodini PL, Imwong M, Polley SD: Two non-recombining sympatric forms of the human malaria parasite Plasmodium ovale occur globally. J Infect Dis 2010, 201:1544-1550

5. Begon M: Ecological epidemiology. In The Princeton Guide to Ecology. Edited by Levin SA, et al. Princeton: Princeton University Press; 2009:220-226.

6. Liu W, Li Y, Learn GH, Rudicell RS, Robertson JD, Keele BF, Ndjango JB, Sanz CM, Morgan DB, Locatelli S, Gonder MK, Kranzusch PJ, Walsh PD, Delaporte E, Mpoudi-Ngole E, Georgiev AV, Muller MN, Shaw GM, Peeters M, Sharp PM, Rayner JC, Hahn BH: Origin of the human malaria parasite Plasmodium falciparum in gorillas. Nature 2010, 467:420-425.

7. Rayner JC, Liu W, Peeters M, Sharp PM, Hahn BH: A plethora of Plasmodium species in wild apes: a source of human infection? Trends Parasitol 2011, 27:222-229.

8. Garamszegi LZ: Patterns of co-speciation and host switching in primate malaria parasites. Malar J 2009, 8:110.

9. Sharp PM, Rayner JC, Hahn BH: Evolution. Great apes and zoonoses. Science 2013, 340:284-286

10. Silva JC, Egan A, Friedman R, Munro JB, Carlton JM, Hughes AL: Genome sequences reveal divergence times of malaria parasite lineages. Parasitology 2011, 138:1737-1749.

11. Dean W: With broadax and firebrand: the destruction of the Brazilian Atlantic Forest. Berkeley: University of California Press; 1995.

12. Ribeiro MC, Metzger JP, Martensen AC, Ponzoni FJ, Hirota MM: The Brazilian Atlantic Forest: How much is left, and how is the remaining forest distributed? Implications for conservation. Biol Conserv 2009, 142:1141-1153.

13. Laporta GZ, Lopez de Prado PI, Kraenkel RA, Coutinho RM, Sallum MA: Biodiversity can help prevent malaria outbreaks in tropical forests. PLoS Negl Trop Dis 2013, 7:e2139.

14. Duarte AM, Pereira DM, de Paula MB, Fernandes A, Urbinatti PR, Ribeiro F, Mello MH, Matos MO Jr, Mucci LF, Fernandes LN, Natal D, Malafronte RS: 
Natural infection in anopheline species and its implications for autochthonous malaria in the Atlantic Forest in Brazil. Parasit Vectors 2013, 6:58

15. Rachou RG: Da infectibilidade dos anofelinos do subgênero Kerteszia pelos parasitas da malária humana. A Folha Med 1946, 27:181-183.

16. Abkallo HM, Liu W, Hokama S, Ferreira PE, Nakazawa S, Maeno Y, Quang NT, Kobayashi N, Kaneko O, Huffman MA, Kawai S, Marchand RP, Carter R, Hahn $\mathrm{BH}$, Culleton R: DNA from pre-erythrocytic stage malaria parasites is detectable by PCR in the faeces and blood of hosts. Int J Parasitol 2014, 44:467-473.

17. Zalis MG, Ferreira-da-Cruz MF, Balthazar-Guedes HC, Banic DM, Alecrim W, Souza JM, Druilhe P, Daniel-Ribeiro CT: Malaria diagnosis: standardization of a polymerase chain reaction for the detection of Plasmodium falciparum parasites in individuals with low-grade parasitemia. Parasitol Res 1996, 82:612-616.

18. Wernsdorfer WH: Global challenges of changing epidemiological patterns of malaria. Acta Trop 2012, 121:158-165.

19. Cerutti C Jr, Boulos M, Coutinho AF, Hatab MCLD, Falqueto A, Rezende HR, Duarte MRC, Collins W, Malafronte RS: Epidemiologic aspects of the malaria transmission cycle in an area of very low incidence in Brazil. Malar J 2007, 6:33.

20. Mendrone A Jr, Cerutti C, Levi JE, Boulos M, Arroyo Sanchez MC, Malafronte RS, di Santi SM, Odone V: Unexpected detection of Plasmodium vivax and Plasmodium falciparum in asymptomatic blood donors: fact or artifact? Malar $J$ 2014, in press.

21. Duarte AMRC, Porto MAL, Curado I, Malafronte RS, Hoffmann EHE, Oliveira SG, Silva AMJ, Kloetzel JK, Gomes AC: Widespread occurrence of antibodies against circumsporozoite protein and against blood forms of Plasmodium vivax, P. falciparum and P. malariae in Brazilian wild monkeys. J Med Primatol 2006, 35:87-96.

22. Yamasaki T, Duarte AMRC, Curado I, Summa MEL, do Valle DDAN, Wunderlich G, Malafronte RS: Detection of etiological agents of malaria in howler monkeys from Atlantic Forests, rescued in regions of São Paulo city, Brazil. J Med Primatol 2011, 40:392-400

23. Duarte AMNRC, Malafronte RS, Cerutti C Jr, Curado I, Paiva BR, Maeda AY, Yamasaki T, Summa MEL, Neves DVDA, Oliveira SG, Gomes AC: Natural Plasmodium infections in Brazilian wild monkeys: Reservoirs for human infections? Acta Trop 2008, 107:179-185.

24. Neves A, Urbinatti PR, Malafronte RS, Fernandes A, Paganini WS, Natal D: Malaria outside the Amazon region: natural Plasmodium infection in anophelines collected near an indigenous village in the Vale do Rio Branco, Itanhaém, SP, Brazil. Acta Trop 2013, 125:102-106.

25. Doderer C, Heschung A, Guntz P, Cazenave P-P, Hansmann Y, Senegas A, Pfaff AW, Abdelrahman T, Candolfi E: A new ELISA kit which uses a combination of Plasmodium falciparum extract and recombinant Plasmodium vivax antigens as an alternative to IFAT doe detection of malaria antibodies. Malar J 2007, 6:19.

26. Oh JS, Kim JS, Lee CH, Nam DH, Kim SH, Park DW, Lee CK, Lim CS, Park GH: Evaluation of a malaria antibody enzyme immunoassay for use in blood screening. Mem Inst Oswaldo Cruz 2008, 103:75-78.

27. Perandin F, Manca N, Calderaro A, Piccolo G, Galati L, Ricci L, Medici MC, Arcangeletti MC, Snounou G, Dettori G, Chezzi C: Development of a real-time PCR assay for detection of Plasmodium falciparum, Plasmodium vivax, and Plasmodium ovale for routine clinical diagnosis. J Clin Microbiol 2004, 42:1214-1219.

28. Gama BE, Silva-Pires FES, Lopes MNR, Cardoso MAB, Britto C, Torres KL, Lima LM, de Souza JM, Daniel-Ribeiro CT, Ferreira-da-Cruz MF: Real-time PCR versus conventional $P C R$ for malaria parasite detection in low-grade parasitemia. Exp Parasitol 2007, 116:427-432.

doi:10.1186/1475-2875-13-337

Cite this article as: Sallum et al:: Finding connections in the unexpected detection of Plasmodium vivax and Plasmodium falciparum DNA in asymptomatic blood donors: a fact in the Atlantic Forest. Malaria Journal 2014 13:337

\section{Submit your next manuscript to BioMed Central and take full advantage of:}

- Convenient online submission

- Thorough peer review

- No space constraints or color figure charges

- Immediate publication on acceptance

- Inclusion in PubMed, CAS, Scopus and Google Scholar

- Research which is freely available for redistribution

Submit your manuscript at www.biomedcentral.com/submit
C Biomed Central 